\title{
Strong Convergence of Monotone Hybrid Algorithm for Hemi-Relatively Nonexpansive Mappings
}

\author{
Yongfu Su, ${ }^{1}$ Dongxing Wang, ${ }^{1}$ and Meijuan Shang ${ }^{1,2}$ \\ ${ }^{1}$ Department of Mathematics, Tianjin Polytechnic University, Tianjin 300160, China \\ ${ }^{2}$ Department of Mathematics, Shijiazhuang University, Shijiazhuang 050035, China
}

Correspondence should be addressed to Yongfu Su, suyongfu@tjpu.edu.cn

Received 1 June 2007; Revised 5 September 2007; Accepted 16 October 2007

Recommended by Simeon Reich

The purpose of this article is to prove strong convergence theorems for fixed points of closed hemirelatively nonexpansive mappings. In order to get these convergence theorems, the monotone hybrid iteration method is presented and is used to approximate those fixed points. Note that the hybrid iteration method presented by S. Matsushita and W. Takahashi can be used for relatively nonexpansive mapping, but it cannot be used for hemi-relatively nonexpansive mapping. The results of this paper modify and improve the results of S. Matsushita and W. Takahashi (2005), and some others.

Copyright (C) 2008 Yongfu Su et al. This is an open access article distributed under the Creative Commons Attribution License, which permits unrestricted use, distribution, and reproduction in any medium, provided the original work is properly cited.

\section{Introduction}

In 2005, Shin-ya Matsushita and Wataru Takahashi [1] proposed the following hybrid iteration method (it is also called the CQ method) with generalized projection for relatively nonexpansive mapping $T$ in a Banach space $E$ :

$$
\begin{aligned}
x_{0} & \in C \quad \text { chosen arbitrarily, } \\
y_{n} & =J^{-1}\left(\alpha_{n} J x_{n}+\left(1-\alpha_{n}\right) J T x_{n}\right), \\
C_{n} & =\left\{z \in C: \phi\left(z, y_{n}\right) \leq \phi\left(z, x_{n}\right)\right\}, \\
Q_{n} & =\left\{z \in C:\left\langle x_{n}-z, J x_{0}-J x_{n}\right\rangle \geq 0\right\}, \\
x_{n+1} & =\prod_{C_{n} \cap Q_{n}}\left(x_{0}\right) .
\end{aligned}
$$

They proved the following convergence theorem. 
Theorem 1.1 (MT). Let E be a uniformly convex and uniformly smooth real Banach space, let $C$ be a nonempty, closed, and convex subset of $E$, let $T$ be a relatively nonexpansive mapping from $C$ into itself, and let $\left\{\alpha_{n}\right\}$ be a sequence of real numbers such that $0 \leq \alpha_{n}<1$ and $\limsup _{n \rightarrow \infty} \alpha_{n}<1$. Suppose that $\left\{x_{n}\right\}$ is given by (1.1), where $J$ is the duality mapping on $E$. If the set $F(T)$ of fixed points of $T$ is nonempty, then $\left\{x_{n}\right\}$ converges strongly to $\Pi_{F(T)} x_{0}$, where $\Pi_{F(T)}(\cdot)$ is the generalized projection from $C$ onto $F(T)$.

The purpose of this article is to prove strong convergence theorems for fixed points of closed hemi-relatively nonexpansive mappings. In order to get these convergence theorems, the monotone hybrid iteration method is presented and is used to approximate those fixed points. Note that the hybrid iteration method presented by S.Matsushita and W. Takahashi can be used for relatively nonexpansive mapping, but it cannot be used for hemi-relatively nonexpansive mapping. The results of this paper modify and improve the results of S.Matsushita and W. Takahashi [1], and some others.

\section{Preliminaries}

Let $E$ be a real Banach space with dual $E^{*}$. We denote by $J$ the normalized duality mapping from $E$ to $2^{E^{*}}$ defined by

$$
J x=\left\{f \in E^{*}:\langle x, f\rangle=\|x\|^{2}=\|f\|^{2}\right\},
$$

where $\langle\cdot, \cdot\rangle$ denotes the generalized duality pairing. It is well known that if $E^{*}$ is uniformly convex, then $J$ is uniformly continuous on bounded subsets of $E$. In this case, $J$ is singe valued and also one to one.

Recall that if $C$ is a nonempty, closed, and convex subset of a Hilbert space $H$ and $P_{C}$ : $H \rightarrow C$ is the metric projection of $H$ onto $C$, then $P_{C}$ is nonexpansive. This is true only when $H$ is a real Hilbert space. In this connection, Alber [2] has recently introduced a generalized projection operator $\Pi_{C}$ in a Banach space $E$ which is an analogue of the metric projection in Hilbert spaces.

Next, we assume that $E$ is a smooth Banach space. Consider the functional defined as $[2,3]$ by

$$
\phi(x, y)=\|x\|^{2}-2\langle x, J y\rangle+\|y\|^{2} \quad \text { for } x, y \in E .
$$

Observe that, in a Hilbert space $H,(2.2)$ reduces to $\phi(x, y)=\|x-y\|^{2}, x, y \in H$.

The generalized projection $\Pi_{C}: E \rightarrow C$ is a map that assigns to an arbitrary point $x \in E$ the minimum point of the functional $\phi(y, x)$, that is, $\Pi_{C} x=\bar{x}$, where $\bar{x}$ is the solution to the minimization problem

$$
\phi(\bar{x}, x)=\min _{y \in C} \phi(y, x)
$$

existence and uniqueness of the operator $\Pi_{C}$ follow from the properties of the functional $\phi(y, x)$ and strict monotonicity of the mapping $J$ (see, e.g., [2-4]). In Hilbert space, $\Pi_{C}=P_{C}$. It is obvious from the definition of the function $\phi$ that

$$
(\|y\|-\|x\|)^{2} \leq \phi(y, x) \leq(\|y\|+\|x\|)^{2} \quad \forall x, y \in E .
$$


Remark 2.1. If $E$ is a reflexive strict convex and smooth Banach space, then for $x, y \in E, \phi(x, y)=$ 0 if and only if $x=y$. It is sufficient to show that if $\phi(x, y)=0$, then $x=y$. From (2.4), we have $\|x\|=\|y\|$. This implies $\langle x, J y\rangle=\|x\|^{2}=\|J y\|^{2}$. From the definition of $J$, we have $J x=J y$, that is, $x=y$; see [5] for more details.

We refer the interested reader to the [6], where additional information on the duality mapping may be found.

Let $C$ be a closed convex subset of $E$, and Let $T$ be a mapping from $C$ into itself. We denote by $F(T)$ the set of fixed points of $T$. $T$ is called hemi-relatively nonexpansive if $\phi(p, T x) \leq \phi(p, x)$ for all $x \in C$ and $p \in F(T)$.

A point $p$ in $C$ is said to be an asymptotic fixed point of $T$ [7] if $C$ contains a sequence $\left\{x_{n}\right\}$ which converges weakly to $p$ such that the strong $\lim _{n \rightarrow \infty}\left(T x_{n}-x_{n}\right)=0$. The set of asymptotic fixed points of $T$ will be denoted by $\widehat{F}(T)$. A hemi-relatively nonexpansive mapping $T$ from $C$ into itself is called relatively nonexpansive $[1,7,8]$ if $\widehat{F}(T)=F(T)$.

We need the following lemmas for the proof of our main results.

Lemma 2.2 (Kamimura and Takahashi [4], [1, Proposition 2.1]). Let E be a uniformly convex and smooth real Banach space and let $\left\{x_{n}\right\},\left\{y_{n}\right\}$ be two sequences of $E$. If $\phi\left(x_{n}, y_{n}\right) \rightarrow 0$ and either $\left\{x_{n}\right\}$ or $\left\{y_{n}\right\}$ is bounded, then $\left\|x_{n}-y_{n}\right\| \rightarrow 0$.

Lemma 2.3 (Alber [2], [1, Proposition 2.2]). Let C be a nonempty closed convex subset of a smooth real Banach space $E$ and $x \in E$. Then, $x_{0}=\Pi_{C} x$ if and only if

$$
\left\langle x_{0}-y, J x-J x_{0}\right\rangle \geq 0 \quad \forall y \in C
$$

Lemma 2.4 (Alber [2], [1, Proposition 2.3]). Let E be a reflexive, strict convex, and smooth real Banach space, let $C$ be a nonempty closed convex subset of $E$ and let $x \in E$. Then

$$
\phi\left(y, \prod_{c} x\right)+\phi\left(\prod_{c} x, x\right) \leq \phi(y, x) \quad \forall y \in C
$$

By using the similar method as [1, Proposition 2.4], the following lemma is not hard to prove.

Lemma 2.5. Let $E$ be a strictly convex and smooth real Banach space, let $C$ be a closed convex subset of $E$, and let $T$ be a hemi-relatively nonexpansive mapping from $C$ into itself. Then $F(T)$ is closed and convex. $T x=y$.

Recall that an operator $T$ in a Banach space is called closed, if $x_{n} \rightarrow x, T x_{n} \rightarrow y$, then

\section{Strong convergence for hemi-relatively nonexpansive mappings}

Theorem 3.1. Theorem 3.1 Let E be a uniformly convex and uniformly smooth real Banach space, let $C$ be a nonempty closed convex subset of $E$, let $T: C \rightarrow C$ be a closed hemi-relatively nonexpansive mapping such that $F(T) \neq \varnothing$. Assume that $\left\{\alpha_{n}\right\}$ is a sequence in $[0,1]$ such that $\lim _{\sup }{ }_{n \rightarrow \infty} \alpha_{n}<1$. Define a sequence $\left\{x_{n}\right\}$ in $C$ by the following algorithm: 


$$
\begin{aligned}
x_{0} & \in C \text { chosen arbitrarily, } \\
y_{n} & =J^{-1}\left(\alpha_{n} J x_{n}+\left(1-\alpha_{n}\right) J T x_{n}\right), \\
C_{n} & =\left\{z \in C_{n-1} \cap Q_{n-1}: \phi\left(z, y_{n}\right) \leq \phi\left(z, x_{n}\right)\right\}, \\
C_{0} & =\left\{z \in C: \phi\left(z, y_{0}\right) \leq \phi\left(z, x_{0}\right)\right\}, \\
Q_{n} & =\left\{z \in C_{n-1} \cap Q_{n-1}:\left\langle x_{n}-z, J x_{0}-J x_{n}\right\rangle \geq 0\right\}, \\
Q_{0} & =C, \\
x_{n+1} & =\prod_{C_{n} \cap Q_{n}}\left(x_{0}\right),
\end{aligned}
$$

where $J$ is the duality mapping on $E$. Then $\left\{x_{n}\right\}$ converges strongly to $\Pi_{F(T)} x_{0}$, where $\Pi_{F(T)}$ is the generalized projection from $C$ onto $F(T)$.

Proof. We first show that $C_{n}$ and $Q_{n}$ are closed and convex for each $n \geq 0$. From the definition of $C_{n}$ and $Q_{n}$, it is obvious that $C_{n}$ is closed and $Q_{n}$ is closed and convex for each $n \geq 0$. We show that $C_{n}$ is convex for any $n \geq 0$. Since

$$
\phi\left(z, y_{n}\right) \leq \phi\left(z, x_{n}\right)
$$

is equivalent to

$$
2\left\langle z, J x_{n}-J y_{n}\right\rangle \leq\left\|x_{n}\right\|^{2}-\left\|y_{n}\right\|^{2},
$$

it follows that $C_{n}$ is convex.

Next, we show that $F(T) \subset C_{n}$ for all $n \geq 0$. Indeed, we have for all $p \in F(T)$ that

$$
\begin{aligned}
\phi\left(p, y_{n}\right) & =\phi\left(p, j^{-1}\left(\alpha_{n} j x_{n}+\left(1-\alpha_{n}\right) j t x_{n}\right)\right) \\
& \leq\|p\|^{2}-2\left\langle p, \alpha_{n} j x_{n}+\left(1-\alpha_{n}\right) j t x_{n}\right\rangle+\alpha_{n}\left\|x_{n}\right\|^{2}+\left(1-\alpha_{n}\right)\left\|t x_{n}\right\|^{2} \\
& =\alpha_{n} \phi\left(p, x_{n}\right)+\left(1-\alpha_{n}\right) \phi\left(p, t x_{n}\right) \\
& \leq \alpha_{n} \phi\left(p, x_{n}\right)+\left(1-\alpha_{n}\right) \phi\left(p, x_{n}\right) \\
& =\phi\left(p, x_{n}\right) .
\end{aligned}
$$

That is, $p \in C_{n}$ for all $n \geq 0$.

Next, we show that $F(T) \subset Q_{n}$ for all $n \geq 0$, we prove this by induction. For $n=0$, we have $F(T) \subset C=Q_{0}$. Assume that $F(T) \subset Q_{n}$. Since $x_{n+1}$ is the projection of $x_{0}$ onto $C_{n} \cap Q_{n}$, by Lemma 2.3, we have

$$
\left\langle x_{n+1}-z, J x_{0}-J x_{n+1}\right\rangle \geq 0, \quad \forall z \in C_{n} \cap Q_{n} .
$$

As $F(T) \subset C_{n} \cap Q_{n}$ by the induction assumptions, the last inequality holds, in particular, for all $z \in F(T)$. This together with the definition of $Q_{n+1}$ implies that $F(T) \subset Q_{n+1}$.

Since $x_{n+1}=\Pi_{C_{n} \cap Q_{n}} x_{0}$ and $C_{n} \cap Q_{n} \subset C_{n-1} \cap Q_{n-1}$ for all $n \geq 1$, we have

$$
\phi\left(x_{n}, x_{0}\right) \leq \phi\left(x_{n+1}, x_{0}\right)
$$

for all $n \geq 0$. Therefore, $\left\{\phi\left(x_{n}, x_{0}\right)\right\}$ is nondecreasing. In addition, it follows from the definition of $Q_{n}$ and Lemma 2.3 that $x_{n}=\Pi_{Q_{n}} x_{0}$. Therefore, by Lemma 2.4, we have

$$
\phi\left(x_{n}, x_{0}\right)=\phi\left(\prod_{Q_{n}} x_{0}, x_{0}\right) \leq \phi\left(p, x_{0}\right)-\phi\left(p, x_{n}\right) \leq \phi\left(p, x_{0}\right),
$$


for each $p \in F(T) \subset Q_{n}$ for all $n \geq 0$. Therefore, $\phi\left(x_{n}, x_{0}\right)$ is bounded, this together with (3.6) implies that the limit of $\left\{\phi\left(x_{n}, x_{0}\right)\right\}$ exists. Put

$$
\lim _{n \rightarrow \infty} \phi\left(x_{n}, x_{0}\right)=d
$$

From Lemma 2.4, we have, for any positive integer $m$, that

$$
\begin{aligned}
\phi\left(x_{n+m}, x_{n}\right) & =\phi\left(x_{n+m}, \prod_{C_{n}} x_{0}\right) \\
& \leq \phi\left(x_{n+m}, x_{0}\right)-\phi\left(\prod_{C_{n}} x_{0}, x_{0}\right)=\phi\left(x_{n+m}, x_{0}\right)-\phi\left(x_{n}, x_{0}\right),
\end{aligned}
$$

for all $n \geq 0$. Therefore,

$$
\lim _{n \rightarrow \infty} \phi\left(x_{n+m}, x_{n}\right)=0
$$

We claim that $\left\{x_{n}\right\}$ is a Cauchy sequence. If not, there exists a positive real number $\varepsilon_{0}>0$ and subsequence $\left\{n_{k}\right\},\left\{m_{k}\right\} \subset\{n\}$ such that

$$
\left\|x_{n_{k}+m_{k}}-x_{n_{k}}\right\| \geq \varepsilon_{0}
$$

for all $k \geq 1$.

On the other hand, from (3.8) and (3.9) we have

$$
\begin{aligned}
\phi\left(x_{n_{k}+m_{k}}, x_{n_{k}}\right) & \leq \phi\left(x_{n_{k}+m_{k}}, x_{0}\right)-\phi\left(x_{n_{k}}, x_{0}\right) \\
& \leq\left|\phi\left(x_{n_{k}+m_{k}}, x_{0}\right)-d\right|+\left|d-\phi\left(x_{n_{k}}, x_{0}\right)\right| \longrightarrow 0, \quad k \longrightarrow \infty
\end{aligned}
$$

Because from (3.8) we know that $\phi\left(x_{n}, x_{0}\right)$ is bounded, this and (2.4) imply that $\left\{x_{n}\right\}$ is also bounded, so by Lemma 2.2 we obtain

$$
\lim _{k \rightarrow \infty}\left\|x_{n_{k}+m_{k}}-x_{n_{k}}\right\|=0
$$

This is a contradiction, so that $\left\{x_{n}\right\}$ is a Cauchy sequence, therefore there exists a point $p \in C$ such that $\left\{x_{n}\right\}$ converges strongly to $p$.

Since $x_{n+1}=\Pi_{C_{n} \cap Q_{n}} x_{0} \in C_{n}$, from the definition of $C_{n}$, we have

$$
\phi\left(x_{n+1}, y_{n}\right) \leq \phi\left(x_{n+1}, x_{n}\right)
$$

It follows from (3.10), (3.14) that

$$
\phi\left(x_{n+1}, y_{n}\right) \longrightarrow 0
$$

By using Lemma 2.2, we have

$$
\lim _{n \rightarrow \infty}\left\|x_{n+1}-y_{n}\right\|=\lim _{n \rightarrow \infty}\left\|x_{n+1}-x_{n}\right\|=0
$$


Since $J$ is uniformly norm-to-norm continuous on bounded sets, we have

$$
\lim _{n \rightarrow \infty}\left\|J x_{n+1}-J y_{n}\right\|=\lim _{n \rightarrow \infty}\left\|J x_{n+1}-J x_{n}\right\|=0
$$

Noticing that

$$
\begin{aligned}
\left\|J x_{n+1}-J y_{n}\right\| & =\left\|J x_{n+1}-\left(\alpha_{n} J x_{n}+\left(1-\alpha_{n}\right) J T x_{n}\right)\right\| \\
& =\left\|\alpha_{n}\left(J x_{n+1}-J x_{n}\right)+\left(1-\alpha_{n}\right)\left(J x_{n+1}-J T x_{n}\right)\right\| \\
& =\left\|\left(1-\alpha_{n}\right)\left(J x_{n+1}-J t x_{n}\right)-\alpha_{n}\left(J x_{n}-J x_{n+1}\right)\right\| \\
& \geq\left(1-\alpha_{n}\right)\left\|J x_{n+1}-J t x_{n}\right\|-\alpha_{n}\left\|J x_{n}-J x_{n+1}\right\|,
\end{aligned}
$$

which implies that

$$
\left\|J x_{n+1}-J T x_{n}\right\| \leq \frac{1}{1-\alpha_{n}}\left(\left\|J x_{n+1}-J y_{n}\right\|+\alpha_{n}\left\|J x_{n}-J x_{n+1}\right\|\right) .
$$

This together with (3.17) and $\limsup _{n \rightarrow \infty} \alpha_{n}<1$ implies that

$$
\lim _{n \rightarrow \infty}\left\|J x_{n+1}-J T x_{n}\right\|=0 \text {. }
$$

Since $J^{-1}$ is also uniformly norm-to-norm continuous on any bounded sets, we have

$$
\lim _{n \rightarrow \infty}\left\|x_{n+1}-T x_{n}\right\|=0
$$

Observe that

$$
\left\|x_{n}-T x_{n}\right\| \leq\left\|x_{n}-x_{n+1}\right\|+\left\|x_{n+1}-T x_{n}\right\|
$$

It follows from (3.16) and (3.21) that

$$
\lim _{n \rightarrow \infty}\left\|x_{n}-T x_{n}\right\|=0
$$

Since $T$ is a closed operator and $x_{n} \rightarrow p$, then $p$ is a fixed point of $T$.

Finally, we prove that $p=\Pi_{F(T)} x_{0}$. From Lemma 2.4, we have

$$
\phi\left(p, \prod_{F(T)} x_{0}\right)+\phi\left(\prod_{F(T)} x_{0}, x_{0}\right) \leq \phi\left(p, x_{0}\right)
$$

On the other hand, since $x_{n+1}=\Pi_{C_{n} \cap Q_{n}}$ and $C_{n} \cap Q_{n} \supset F(T)$, for all $n$, we get from Lemma 2.4 that

$$
\phi\left(\prod_{F(T)} x_{0}, x_{n+1}\right)+\phi\left(x_{n+1}, x_{0}\right) \leq \phi\left(\prod_{F(T)} x_{0}, x_{0}\right) .
$$

By the definition of $\phi(x, y)$, it follows that both $\phi\left(p, x_{0}\right) \leq \phi\left(\Pi_{F(T)} x_{0}, x_{0}\right)$ and $\phi\left(p, x_{0}\right) \geq$ $\phi\left(\Pi_{F(T)} x_{0}, x_{0}\right)$, whence $\phi\left(p, x_{0}\right)=\phi\left(\Pi_{F(T)} x_{0}, x_{0}\right)$. Therefore, it follows from the uniqueness of $\Pi_{F(T)} x_{0}$ that $p=\Pi_{F(T)} x_{0}$. This completes the proof. 
Theorem 3.2. Let $E$ be a uniformly convex and uniformly smooth real Banach space, let $C$ be a nonempty, closed, and convex subset of $E$, and let $T: C \rightarrow C$ be a closed relative nonexpansive mapping such that $F(T) \neq \varnothing$. Assume that $\left\{\alpha_{n}\right\}$ is a sequences in $[0,1]$ such that lim $\sup _{n \rightarrow \infty} \alpha_{n}<1$. Define a sequence $\left\{x_{n}\right\}$ in $C$ by the following algorithm:

$$
\begin{aligned}
x_{0} & \in C \text { chosen arbitrarily, } \\
y_{n} & =J^{-1}\left(\alpha_{n} J x_{n}+\left(1-\alpha_{n}\right) J T x_{n}\right), \\
C_{n} & =\left\{z \in C_{n-1} \cap Q_{n-1}: \phi\left(z, y_{n}\right) \leq \phi\left(z, x_{n}\right)\right\}, \\
C_{0} & =\left\{z \in C: \phi\left(z, y_{0}\right) \leq \phi\left(z, x_{0}\right)\right\}, \\
Q_{n} & =\left\{z \in C_{n-1} \cap Q_{n-1}:\left\langle x_{n}-z, J x_{0}-J x_{n}\right\rangle \geq 0\right\}, \\
Q_{0} & =C, \\
x_{n+1} & =\prod_{C_{n} \cap Q_{n}}\left(x_{0}\right),
\end{aligned}
$$

where $J$ is the duality mapping on $E$. Then $\left\{x_{n}\right\}$ converges strongly to $\Pi_{F(T)} x_{0}$, where $\Pi_{F(T)}$ is the generalized projection from $C$ onto $F(T)$.

Proof. Since every relatively nonexpansive mapping is a hemi-relatively one, Theorem 3.2 is implied by Theorem 3.1.

Remark 3.3. In recent years, the hybrid iteration methods for approximating fixed points of nonlinear mappings have been introduced and studied by various authors [1,8-11]. In fact, all hybrid iteration methods can be replaced (or modified) by monotone hybrid iteration methods, respectively. In addition, by using the monotone hybrid method we can easily show that the iteration sequence $\left\{x_{n}\right\}$ is a Cauchy sequence, without the use of the Kadec-Klee property, demiclosedness principle, and Opial's condition or other methods which make use of the weak topology.

\section{Acknowledgments}

The authors would like to thank the referee for valuable suggestions which helped to improve this manuscript. This project is supported by the National Natural Science Foundation of China under Grant no. 10771050.

\section{References}

[1] S.-Y. Matsushita and W. Takahashi, "A strong convergence theorem for relatively nonexpansive mappings in a banach space," Journal of Approximation Theory, vol. 134, no. 2, pp. 257-266, 2005.

[2] Ya. I. Alber, "Metric and generalized projection operators in Banach spaces: properties and applications," in Theory and Applications of Nonlinear Operators of Accretive and Monotone Type, A. G. Kartsatos, Ed., vol. 178 of Lecture Notes in Pure and Appl. Math., pp. 15-50, Marcel Dekker, New York, NY, USA, 1996.

[3] Ya. I. Alber and S. Reich, "An iterative method for solving a class of nonlinear operator equations in Banach spaces," PanAmerican Mathematical Journal, vol. 4, no. 2, pp. 39-54, 1994.

[4] S. Kamimura and W. Takahashi, "Strong convergence of a proximal-type algorithm in a Banach space," SIAM Journal on Optimization, vol. 13, no. 3, pp. 938-945, 2002.

[5] I. Cioranescu, Geometry of Banach Spaces, Duality Mappings and Nonlinear Problems, vol. 62 of Mathematics and Its Applications, Kluwer Academic, Dordrecht, The Netherlands, 1990. 
[6] S. Reich, "Review of geometry of Banach spaces, duality mappings and nonlinear problems by Ioana Cioranescu," Bulletin of the American Mathematical Society, vol. 26, pp. 367-370, 1992.

[7] D. Butnariu, S. Reich, and A. J. Zaslavski, "Asymptotic behavior of relatively nonexpansive operators in Banach spaces," Journal of Applied Analysis, vol. 7, no. 2, pp. 151-174, 2001.

[8] C. Martinez-Yanes and H.-K. Xu, "Strong convergence of the CQ method for fixed point iteration processes," Nonlinear Analysis: Theory, Methods \& Applications, vol. 64, no. 11, pp. 2400-2411, 2006.

[9] T.-H. Kim and H.-K. Xu, "Strong convergence of modified Mann iterations for asymptotically nonexpansive mappings and semigroups," Nonlinear Analysis: Theory, Methods E Applications, vol. 64, no. 5, pp. 1140-1152, 2006.

[10] K. Nakajo and W. Takahashi, "Strong convergence theorems for nonexpansive mappings and nonexpansive semigroups," Journal of Mathematical Analysis and Applications, vol. 279, no. 2, pp. 372-379, 2003.

[11] X. Qin and Y. Su, "Strong convergence theorems for relatively nonexpansive mappings in a banach space," Nonlinear Analysis: Theory, Methods \& Applications, vol. 67, no. 6, pp. 1958-1965, 2007. 